PALABRAS CLAVE

Clase media

Condiciones económicas

Condiciones sociales

Indicadores económicos

Datos estadísticos

Hogares

Empleo

Ingresos

América Latina

Rolando Franco

Consultor ILPES/CEPAL

œ rolando.franco.diaz@gmail.com

Martín Hopenhayn

Director de la División de Desarrollo

Social de la CEPAL

martin.hopenhayn@cepal.org

Arturo León

Consultor de la CEPAL

- aleonb@movistar.cl
REVISTA CEPAL 103 • ABRIL 2011

\section{Crece y cambia la clase media en América Latina: una puesta al día}

\author{
Rolando Franco, Martin Hopenhayn y Arturo León
}

$\mathrm{E}$

n este trabajo se utiliza una definición bidimensional de clase media, en que se combinan la ocupación del principal proveedor de ingreso del hogar (manual, no manual) y el ingreso familiar como una variable sustitutiva del consumo. Esto permite explorar los cambios "objetivos" de la clase media en América Latina entre 1990 y 2007. Se analizan los cambios "subjetivos" en valores, aspiraciones e identidad de clase, entre otros. Resalta el crecimiento tanto relativo como absoluto de los sectores medios, así como el incremento generalizado de la educación, opacado por la devaluación de su importancia relativa para generar ingreso, y la menor relevancia de la diferencia entre ocupaciones manuales y no manuales de nivel bajo como determinante del ingreso. La heterogeneidad de los estratos medios se evidencia tanto en cortes verticales como horizontales, relacionados con diferentes tipos de riesgos y niveles de bienestar característicos de los hogares de cada segmento. 


\section{I}

\section{Introducción}

En este artículo se analizan los grandes cambios que se han producido en las últimas dos décadas en la magnitud de la clase media latinoamericana, así como en su composición y perfiles. También se intenta explorar la manera en que estas modificaciones han alterado los patrones valóricos, aspiracionales y de identidad de clase de las sociedades de América Latina.

La expansión de los estratos medios no ha sido un fenómeno exclusivo de la región y forma parte de una tendencia global. Así, el Banco Mundial (2006) llamó la atención sobre la existencia de 1.300 millones de personas de clase media en el mundo, especialmente en países como China y la India. Goldman Sachs destaca la expansión inédita de las personas con ingresos de nivel medio, conglomerado que vendría creciendo a razón de
70 millones de personas por año y que en el año 2030 llegaría a los 2.000 millones de personas, vale decir, alrededor del $30 \%$ de la población mundial (Wilson y Dragusanu, 2008, pág. 3).

Una vez constatado el carácter universal del fenómeno, se analizan a continuación los procesos específicos que tuvo la expansión de las clases medias en un grupo importante de países de América Latina. La información incluye a 10 países que representan el $80 \%$ de la población regional. El libro en que se basa este artículo (Franco, Hopenhayn y León, 2010) comprende además estudios de casos nacionales de cinco países que conforman el $65 \%$ de la población latinoamericana. Empero, antes de compenetrarse en los datos es necesario detenerse en el concepto mismo de clases o estratos medios, que suele resultar elusivo.

\section{II \\ ¿De qué hablamos cuando hablamos de clases medias? Hacia una definición bidimensional}

El estudio de la clase media presenta dificultades especiales, entre las que se mencionan las siguientes:

i) La pluralidad o ausencia de definiciones, que conduce a imputar atributos a grupos equivocados.

ii) La hipérbole conceptual, es decir, la extensión a un colectivo difícil de aprehender de las observaciones realizadas respecto de un pequeño grupo que no es representativo del conjunto.

iii) La amalgama, vale decir, la utilización de atributos de distintos grupos para conformar un tipo ideal de clase media (Escobar y Pedraza, 2010).

En este estudio se intenta superar esos riesgos recurriendo a un enfoque en que se emplean, por una parte, dimensiones objetivas como la ocupación, el ingreso, la educación y el consumo, y se exploran, por otra, aspectos subjetivos tales como valores y aspiraciones, o la adopción de determinados estilos de vida y mecanismos con que se procura establecer "distinción” (en el sentido de distinguirse, separarse) respecto de otros estratos sociales. Se entiende que recurrir a ambas perspectivas permite una aproximación más amplia y cabal al objeto de estudio, a saber, las clases medias latinoamericanas contemporáneas.

En la primera aproximación se realiza un análisis comparativo entre países para captar los cambios ocurridos en un período relativamente prolongado (1990-2007), utilizando información procedente de encuestas de hogares que permite apreciar el tamaño de dichos estratos y sus características. Cabe advertir que echar mano a esta fuente de información condiciona las opciones metodológicas disponibles, como se verá más adelante.

Tradicionalmente, la ocupación ha sido considerada como la dimensión clave para captar las diferencias en el interior de la sociedad. Esta dimensión es la que está en la base de los principales estudios y teorías sobre estratificación social. Mientras que el grupo alto estaría constituido por empleadores y rentistas, el resto de la población se divide entre quienes ejecutan empleos manuales y aquellos que realizan actividades no manuales o de "cuello blanco". Esto implicaría el desempeño de un trabajo "intelectual”, que en general iría acompañado de estabilidad laboral y de cierto nivel 
de prosperidad material. Sin embargo, en la actualidad se ha atenuado el vínculo entre el tipo de ocupación y el nivel de ingreso.

Por consiguiente, en muchos estudios se ha considerado preferible recurrir al ingreso para identificar los estratos. De este modo, la clase media se ha definido identificando taxativamente los deciles intermedios de la distribución o, alternativamente, estableciendo valores fijos en torno de la mediana. La limitación de este procedimiento es que no permite encontrar diferencias en la magnitud de la clase media cuando se analizan países diversos. ${ }^{1}$ Ello sí resulta posible cuando se recurre a la ocupación (manual, no manual) como diferenciadora entre estratos medios y bajos. En este caso, el volumen relativo de dicha clase varía significativamente según el país en función de su nivel de desarrollo, lo que incluye el grado de urbanización, la diferenciación productiva, la tercerización del empleo y el nivel educacional de la población, entre otros factores. ${ }^{2}$ Conviene recordar, además, que la delimitación de grupos sociales sobre la base exclusiva del ingreso enfrenta problemas de confiabilidad de los datos en las propias encuestas y ante la alta variabilidad de situaciones de empleo en una misma franja de la distribución del ingreso.

Dadas las ventajas y limitaciones derivadas de utilizar aisladamente las variables mencionadas para definir las clases, en este trabajo se ha optado por combinar dos de ellas en un constructo que tiene las siguientes características:

i) Se sostiene que la ocupación sigue siendo relevante para el objetivo buscado, pero también que el ingreso es importante no solo porque permite fijar el nivel económico correspondiente a cada estrato, sino también porque es una variable sustitutiva (proxy) de la capacidad de consumo y del acceso al bienestar de los hogares. ${ }^{3}$ En el cuadro 1 se precisa la terminología y la estrategia empírica para delimitar estratos sociales medios (ESM) en el conjunto de la población.

\footnotetext{
${ }^{1}$ Obviamente las hay cuando la delimitación de los estratos se basa en particiones de la distribución personal o familiar del ingreso, a partir de ciertos límites o valores fijos o tramos de ingreso.

2 Integra el estrato manual la población ocupada en actividades agrícolas y en silvicultura y pesca (Gran Grupo 6 de la Clasificación Internacional Uniforme de Ocupaciones (CIUO 88)).

${ }^{3} \mathrm{El}$ caso más claro se refiere a la posibilidad de acceder a créditos para la adquisición de viviendas. Los bancos y entidades financieras otorgan esos créditos no solo mediante la evaluación de la capacidad económica del solicitante o titular de préstamos, sino sobre la base del ingreso familiar.
}

CUADRO 1

Estratos de ingreso

\begin{tabular}{lccc}
\hline \multirow{2}{*}{ Estratos laborales } & \multicolumn{3}{c}{ Estratos } \\
\cline { 2 - 4 } & Alto & Medio & Bajo \\
\hline Alto & ESM & \\
Medio & ESM & ESM \\
Bajo & ESM & \\
\hline
\end{tabular}

ii) Se relacionan el ingreso familiar y la inserción ocupacional por medio del principal perceptor de ingresos del hogar (PPIH), vale decir, del integrante del grupo familiar - no necesariamente el jefe de hogar-que percibe el mayor ingreso monetario, ingreso que puede provenir del trabajo (asalariado o independiente), del capital (rentas, utilidades y dividendos) o de transferencias (jubilaciones, pensiones, transferencias de programas sociales, remesas del exterior y de otros hogares). Por tanto, entre los PPIH hay también inactivos, lo que incluye a rentistas, jubilados y perceptores de ingresos por transferencias no provenientes del trabajo.

iii) A diferencia de las investigaciones sobre estratificación y movilidad social, se toma como unidad de análisis el "hogar" y no el individuo, lo que posibilita abordar temas como el tamaño de la familia, la "homogamia" de clase, la conformación del ingreso familiar (según el número de miembros activos en el hogar), entre otros. Estos temas no pueden estudiarse cuando la estratificación se basa únicamente en la inserción ocupacional de los individuos, con independencia del hogar de que forman parte. Asimismo, a diferencia de lo usual en ese tipo de investigaciones, se incluye a todos los hogares y no solo a aquellos cuyo PPIH está ocupado. ${ }^{4}$

iv) Las fronteras de la clase media se establecieron a partir de la distribución del ingreso de los PPIH. Como límite inferior se consideró el monto correspondiente al cuádruple del valor de la línea de

\footnotetext{
${ }^{4}$ En estas últimas, a partir de la definición de estratos ocupacionales, se analizan las trayectorias laborales de las personas durante su vida activa o se compara la posición ocupacional de los hijos en edad activa con la de sus padres. Se excluye a los cesantes — por falta de información sobre su último empleo- y también a la población inactiva (jubilados, pensionados, rentistas). Algunos estudios abarcan solo a una parte de los ocupados, por ejemplo, a los varones o a los ocupados de ciertos grupos de edades. Así sucede cuando se utilizan datos primarios basados en cuestionarios ad hoc aplicados a una muestra de la población.
} 
pobreza urbana, ${ }^{5}$ y como límite superior se adoptó el valor del percentil 95 de dicha distribución. De esta manera, el estrato medio de ingreso quedó conformado por los hogares en que el PPIH declaró ingresos comprendidos entre los valores indicados. Nótese, empero, que se consideró el ingreso familiar total (la suma de recursos monetarios aportados por todos sus miembros) como variable de estratificación. ${ }^{6}$

v) La distinción entre ocupaciones manuales y no manuales se realizó utilizando la Clasificación Internacional Uniforme de Ocupaciones (CIUO) de la Organización Internacional del Trabajo, con un nivel de desagregación de un dígito (Grandes grupos), la que debe ajustarse para hacerla consistente con la incorporación del ingreso en la definición de los estratos medios. ${ }^{7}$ Los PPIH asalariados y por cuenta propia que declararon desempeñarse en ocupaciones pertenecientes a los Grandes grupos 1 a 5 de la ciuo forman parte del estrato laboral medio; los que se desempeñan en ocupaciones de los Grandes grupos 6 a 9 (incluido el grupo 0 de las fuerzas armadas) son de nivel bajo. ${ }^{8}$ El estrato alto quedó conformado por empleadores y rentistas, cuando el PPIH es inactivo. Los jubilados se consideraron perceptores de estratos medios (véase el cuadro 2).

\footnotetext{
${ }^{5}$ Esas líneas de pobreza estimadas por la CEPAL corresponden a un monto de ingreso que varía según los países. Véase CEPAL (2008a, Anexo estadístico, cuadro 6).

${ }^{6}$ Dichos valores se calcularon para el último año disponible en cada país y luego se aplicaron al año inicial. Previamente, los ingresos en moneda corriente de las encuestas de cada país y año se expresaron en dólares del año 2000, en valores de poder adquisitivo de paridad a fin de realizar comparaciones en el tiempo y entre los países. En el cuadro 1 se resumen los límites de ingreso utilizados y se los compara con la mediana de la distribución del ingreso total de los hogares. A cada perceptor principal de ingreso se le vincula o le corresponde un ingreso familiar constituido por la suma de los ingresos monetarios (de las tres corrientes indicadas más arriba) de todos los integrantes del respectivo hogar.

${ }^{7}$ En el año inicial, muchas de las clasificaciones utilizadas en las encuestas nacionales corresponden a adaptaciones de la cIUO 68, mientras que en el año final corresponden generalmente a la ciUo 88. No obstante, en algunos países la clasificación de la población activa según ocupaciones y oficios difiere absolutamente de las recomendaciones de la OIT, como sucede en la encuesta de hogares de la Argentina.

${ }^{8}$ En las ocupaciones no manuales se incluye a miembros de los poderes del Estado; personal directivo de la administración pública; directores y gerentes de empresas; profesionales, científicos e intelectuales y técnicos y profesionales de nivel medio; empleados de oficina y trabajadores calificados de los servicios y vendedores de comercio. En las ocupaciones manuales se incluye a agricultores y trabajadores agropecuarios y pesqueros, operarios, artesanos, mecánicos e instaladores, trabajadores no calificados de ventas y servicios y a los peones.
}

CUADRO 2

\section{Criterio utilizado para delimitar los estratos laborales}

\begin{tabular}{|c|c|c|c|}
\hline \multirow{2}{*}{$\begin{array}{l}\text { Principales perceptores } \\
\text { de ingreso }\end{array}$} & \multicolumn{3}{|c|}{ Estratos laborales } \\
\hline & Alto & Medio & Bajo \\
\hline \multicolumn{4}{|l|}{ Ocupados } \\
\hline Empleadores & $\mathrm{X}$ & & \\
\hline $\begin{array}{l}\text { Trabajadores por cuenta propia } \\
\text { en ocupaciones no manuales } \\
\text { en ocupaciones manuales }\end{array}$ & & $\mathrm{x}$ & $\mathrm{x}$ \\
\hline $\begin{array}{l}\text { Asalariados públicos y privados } \\
\text { en ocupaciones no manuales } \\
\text { en ocupaciones manuales }\end{array}$ & & $\mathrm{x}$ & $\mathrm{x}$ \\
\hline \multicolumn{4}{|l|}{ No ocupados } \\
\hline $\begin{array}{l}\text { Rentistas } \\
\text { Jubilados } \\
\text { Resto inactivos }^{\mathrm{c}}\end{array}$ & $\mathrm{X}$ & $\mathrm{x}$ & $\mathrm{X}$ \\
\hline
\end{tabular}

Fuente: elaboración propia.

a Grandes grupos 1 a 5 de la Clasificación Internacional Uniforme de Ocupaciones (CIUo 88) de la Organización Internacional del Trabajo (OIT).

b Grandes grupos 6 a 9 y Grupo 0 de la Clasificación Internacional Uniforme de Ocupaciones (CIUo 88) de la OIT.

c Incluye a principales perceptores de ingresos de los hogares (PPIH) con ingresos provenientes de remesas, transferencias monetarias de programas sociales y otros ingresos no provenientes del trabajo.

vi) Se establecieron ciertos valores absolutos de ingreso (en términos reales) que deben mantenerse en el tiempo, lo que permite indagar en qué medida los cambios en el nivel y distribución del ingreso inciden en el tamaño absoluto y relativo de los estratos medios. Se descartaron otras alternativas utilizadas en estudios recientes en que se adopta el ingreso como criterio para delimitar estratos, en particular los que basan su conformación en ciertos deciles intermedios de la distribución del ingreso (Solimano, 2008), o que recurren a algún parámetro de la distribución del ingreso - la mediana, por ejemplo- - y definen al estrato medio como el conjunto de hogares que se encuentran sobre y debajo de cierta fracción del valor de ese parámetro, por ejemplo: entre 0,75 y 1,25 veces el valor de la mediana de la distribución del ingreso per cápita de los hogares (Birdsall, Graham y Pettinato, 2000). Si bien estas aproximaciones permiten apreciar cambios en el tamaño absoluto del estrato, no pueden registrar cambios 
en su tamaño relativo (la basada en percentiles fijos, por definición) o solo aquellos derivados de cambios en la distribución del ingreso en torno del valor de la mediana. Esas variaciones son relativamente pequeñas, debido a que la distribución del ingreso en los países de la región no ha experimentado cambios muy significativos, sobre todo respecto de los deciles intermedios. De 1990 a 2006 la participación en el ingreso de los hogares comprendidos entre los deciles 5 y 9 registró cambios absolutos de 1 a 4 puntos porcentuales en 9 de los 10 países seleccionados. La excepción es Honduras donde se observó un aumento de seis puntos (véase CEPAL, 2008a, Anexo estadístico, cuadro 12).

vii) Se utilizó el ingreso familiar total como variable representativa de la capacidad de consumo, opción que difiere de la usada habitualmente en los estudios de pobreza, que recurren al ingreso per cápita del hogar.

viii) El tamaño de la clase media no es fijo, sino que varía según el nivel de desarrollo de cada país. El valor de cuatro veces la línea de pobreza urbana como fracción de la mediana de la distribución (véase la última columna del cuadro 3) guarda estrecha relación con el nivel de ingreso por habitante, ${ }^{9}$ con el porcentaje de población urbana, con el nivel de educación de la población, con el ingreso y el consumo promedio de los hogares, con el grado de "asalarización" y con la diversificación de la estructura productiva de los países, que va acompañada del crecimiento del sector terciario y en particular de las ocupaciones típicas de clase media, no manuales o de "cuello blanco". Asimismo, la posición relativa del valor que delimita al estrato medio del estrato de ingreso bajo (tercera y cuarta columnas del cuadro 3) cambia entre los años inicial y final de acuerdo con la variación del crecimiento económico de los países. Ello muestra que una parte del aumento de los estratos sociales medios en el período examinado provino del incremento del ingreso y del consumo de la población del estrato de bajos ingresos. En síntesis, el procedimiento para determinar los límites de ingreso permite establecer comparaciones entre países y poner de relieve la incidencia del acrecentamiento del ingreso y de los cambios distributivos de los últimos 15 años en la estratificación social en la región.

${ }^{9}$ A mayor ingreso por habitante menor es el cuociente entre 4 líneas de pobreza (LP) y la mediana de la distribución del ingreso de los hogares.

CUADRO 3

América Latina (10 países, diversos períodos): valores utilizados para clasificar a los hogares según estratos de ingreso

(Salarios mensuales en dólares de 2000 medidos en paridad de poder adquisitivo)

\begin{tabular}{|c|c|c|c|c|c|}
\hline País & Período & 4LP per cápita ${ }^{\mathrm{a}}$ & Percentil 95b & 4LP / Mediana ${ }^{c}$ & 4LP / Mediana ${ }^{\mathrm{d}}$ \\
\hline Argentina $\mathrm{e}^{\mathrm{e}}$ & $1990-2006$ & 976 & 4522 & 0,65 & 0,62 \\
\hline Brasil & $1990-2007$ & 792 & 3397 & 1,39 & 0,96 \\
\hline Chile & $1990-2006$ & 552 & 3569 & 0,88 & 0,52 \\
\hline Colombia & $1991-2005$ & 969 & 3259 & 1,10 & 1,09 \\
\hline Costa Rica & $1990-2007$ & 687 & 2950 & 0,84 & 0,63 \\
\hline Honduras & $1990-2007$ & 790 & 1560 & 2,51 & 1,73 \\
\hline Panamá & $1991-2007$ & 514 & 2254 & 0,93 & 0,65 \\
\hline Perú & $1997-2003$ & 681 & 1674 & 1,18 & 1,30 \\
\hline República Dominicana & $1997-2007$ & 887 & 2241 & 0,88 & 1,11 \\
\hline
\end{tabular}

Fuente: Comisión Económica para América Latina y el Caribe (CEPAL), sobre la base de tabulaciones especiales de encuestas de hogares de los países.

a Corresponde a cuatro veces el valor de la línea de pobreza urbana de cada país.

b Corresponde al percentil 95 de la distribución del ingreso de los principales perceptores de los hogares.

c 4 líneas de pobreza como fracción de la mediana de la distribución del ingreso total de los hogares del año inicial.

d 4 líneas de pobreza como fracción de la mediana de la distribución del ingreso total de los hogares del año final.

e Gran Buenos Aires. 


\section{III}

\section{Transformaciones y rasgos actuales}

\section{de la clase media}

Los cambios ocurridos en el período bajo examen (19902006/2007) se originan en la expansión del empleo no manual y el crecimiento de la capacidad de consumo de los hogares, como se muestra a continuación.

\section{Magnitud y evolución del estrato medio desde la perspectiva ocupacional}

Desde fines de los años ochenta continuó expandiéndose el empleo no manual. En dos países (la Argentina y Chile) algo más de la mitad de los hogares forman parte del estrato medio. ${ }^{10}$ En el Brasil, el $46 \%$ pertenece a ese estrato. En tres de los países considerados abarca a alrededor del $40 \%$, mientras que en otros tres es del orden del $30 \%$; en el restante comprende a un cuarto de los hogares.

\footnotetext{
${ }^{10}$ Aunque se refiere al Gran Buenos Aires, es muy probable que ese dato sea representativo a nivel nacional debido al alto grado de urbanización de la Argentina (más de $85 \%$ de la población reside en zonas urbanas).
}

\section{Incorporación al estrato medio por ampliación de la capacidad de consumo}

En los países analizados, en una misma generación se ha producido un significativo crecimiento absoluto del producto interno bruto (PIB) por habitante, que incrementó el ingreso (y por tanto el consumo) de los hogares medios y bajos (véase el cuadro 4). ${ }^{11}$ Ello condujo a que la distribución según tramos de ingreso de los hogares de los estratos laborales medio y bajo tuviera un "desplazamiento" desde el tramo de menos de 5.000 dólares anuales (por familia, en moneda de igual poder adquisitivo) hacia el tramo intermedio (de entre 5.000 y 15.000 dólares anuales) e incluso al tramo superior (más de 15.000 dólares). ${ }^{12}$ Este desplazamiento se registró en casi todos los países (véase el cuadro 5).

\footnotetext{
${ }^{11}$ Los principales perceptores de ingreso del hogar (PPIH), que en 1990 tenían 30 años de edad, hoy tienen menos de 50. Por tanto, los cambios en el ingreso registran procesos de movilidad dentro de una misma generación.

12 Este cambio - muy importante desde la perspectiva de la estratificación social— no puede apreciarse en los análisis de la distribución del ingreso entre deciles o quintiles de hogares.
}

CUADRO 4

América Latina (10 países, diversos períodos): nivel y variación del PIB por habitante (Salarios mensuales en dólares de 2000 medidos en paridad de poder adquisitivo)

\begin{tabular}{|c|c|c|c|c|c|c|}
\hline País & Período & Año inicial & Año final & Aumento absoluto & Aumento porcentual & Tasa de crecimiento anual \\
\hline Argentina & $1990-2006$ & 8781 & 13652 & 4871 & 55,5 & 2,8 \\
\hline Brasil & $1990-2007$ & 6480 & 8152 & 1672 & 25,8 & 1,4 \\
\hline Chile & $1990-2006$ & 5744 & 10939 & 5194 & 90,4 & 4,1 \\
\hline Colombia & $1991-2005$ & 5590 & 6536 & 945 & 16,9 & 1,1 \\
\hline Costa Rica & $1990-2007$ & 6268 & 9067 & 2799 & 44,6 & 2,2 \\
\hline Honduras & $1990-2007$ & 2744 & 3312 & 568 & 20,7 & 1,1 \\
\hline México & $1989-2006$ & 7517 & 9967 & 2450 & 32,6 & 1,7 \\
\hline Panamá & $1991-2007$ & 4842 & 7917 & 3075 & 63,5 & 3,1 \\
\hline Perú & $1997-2003$ & 4812 & 4942 & 130 & 2,7 & 0,4 \\
\hline República Dominicana & $1997-2007$ & 5359 & 8149 & 2790 & 52,1 & 4,3 \\
\hline Argentina & $1990-1999$ & 8781 & 12322 & 3541 & 40,3 & 3,8 \\
\hline Argentina & $1999-2002$ & 12322 & 10098 & -2224 & $-18,0$ & $-6,4$ \\
\hline Argentina & $2002-2006$ & 10098 & 13652 & 3555 & 35,2 & 10,6 \\
\hline
\end{tabular}

Fuente: elaboración propia a partir de información de las bases de datos del Banco Mundial.

PIB: producto interno bruto. 
CUADRO 5

América Latina (10 países, diversos años): distribución de los hogares según tramos de ingreso familiara y estrato laboral $^{\mathrm{b}}$

\begin{tabular}{|c|c|c|c|c|c|c|}
\hline & Estrato medio & $\begin{array}{l}\text { Estrato bajo } \\
\text { (Año) }\end{array}$ & Total & Estrato medio & $\begin{array}{l}\text { Estrato bajo } \\
\quad \text { (Año) }\end{array}$ & Total \\
\hline Argentina $^{\mathbf{c}}$ & & (1990) & & & (2006) & \\
\hline Hasta 5000 & 5 & 15 & 11 & 3 & 9 & 6 \\
\hline 5001 a 15000 & 33 & 34 & 32 & 31 & 37 & 32 \\
\hline Más de 15000 & 63 & 51 & 58 & 66 & 54 & 62 \\
\hline Brasil & & (1990) & & & (2007) & \\
\hline Hasta 5000 & 30 & 50 & 40 & 14 & 33 & 23 \\
\hline 5001 a 15000 & 35 & 36 & 35 & 43 & 47 & 44 \\
\hline Más de 15000 & 35 & 14 & 25 & 43 & 20 & 33 \\
\hline Chile & & (1990) & & & (2006) & \\
\hline Hasta 5000 & 23 & 41 & 32 & 12 & 20 & 15 \\
\hline 5001 a 15000 & 43 & 45 & 43 & 36 & 52 & 42 \\
\hline Más de 15000 & 35 & 14 & 25 & 53 & 28 & 43 \\
\hline Colombia & & (1991) & & & (2005) & \\
\hline Hasta 5000 & 16 & 20 & 18 & 10 & 26 & 20 \\
\hline 5001 a 15000 & 39 & 52 & 47 & 33 & 51 & 44 \\
\hline Más de 15000 & 45 & 28 & 35 & 58 & 23 & 36 \\
\hline Costa Rica & & (1990) & & & (2007) & \\
\hline Hasta 5000 & 10 & 26 & 19 & 9 & 21 & 15 \\
\hline 5001 a 15000 & 43 & 54 & 49 & 33 & 51 & 42 \\
\hline Más de 15000 & 46 & 21 & 33 & 58 & 28 & 43 \\
\hline Honduras & & (1990) & & & (2007) & \\
\hline Hasta 5000 & 27 & 69 & 60 & 20 & 58 & 47 \\
\hline 5001 a 15000 & 43 & 27 & 30 & 43 & 34 & 36 \\
\hline Más de 15000 & 30 & 5 & 10 & 37 & 9 & 17 \\
\hline México & & (1989) & & & (2006) & \\
\hline Hasta 5000 & 11 & 27 & 21 & 8 & 20 & 14 \\
\hline 5001 a 15000 & 47 & 53 & 50 & 40 & 55 & 47 \\
\hline Más de 15000 & 43 & 20 & 30 & 52 & 25 & 38 \\
\hline Panamá & & (1991) & & & (2007) & \\
\hline Hasta 5000 & 17 & 54 & 39 & 12 & 37 & 26 \\
\hline 5001 a 15000 & 45 & 36 & 40 & 44 & 44 & 43 \\
\hline Más de 15000 & 38 & 10 & 21 & 43 & 19 & 31 \\
\hline Perú & & (1997) & & & (2003) & \\
\hline Hasta 5000 & 14 & 48 & 37 & 15 & 52 & 41 \\
\hline 5001 a 15000 & 48 & 41 & 43 & 50 & 40 & 43 \\
\hline Más de 15000 & 38 & 11 & 20 & 36 & 8 & 17 \\
\hline República Dominicana & & (1997) & & & (2007) & \\
\hline Hasta 5000 & 6 & 19 & 15 & 18 & 37 & 30 \\
\hline 5001 a 15000 & 36 & 49 & 45 & 39 & 36 & 36 \\
\hline Más de 15000 & 58 & 32 & 40 & 43 & 27 & 35 \\
\hline
\end{tabular}

Fuente: Comisión Económica para América Latina y el Caribe (CEPAL), sobre la base de tabulaciones especiales de encuestas de hogares de los países.

a Los tramos de ingreso corresponden a ingreso anual, en salarios mensuales en dólares de 2000 medidos en paridad de poder adquisitivo.

b Por efecto de redondeo algunas columnas no suman $100 \%$.

c Gran Buenos Aires. 
Por lo tanto, se produjo un importante incremento de la capacidad de consumo de los hogares del estrato medio y bajo, pero sin cambios muy significativos en la (muy concentrada) distribución del ingreso. ${ }^{13}$ Debido a ello hubo contingentes de trabajadores manuales que alcanzaron ingresos aun superiores a los de los asalariados no manuales, cuyas retribuciones no aumentaron al mismo ritmo o incluso experimentaron un descenso durante el período examinado.

Ese cambio favorable en los ingresos del estrato bajo, muy pronunciado en el Brasil, Chile y Panamá, se vio reforzado por la expansión del crédito destinado al consumo y la adquisición de viviendas, y por la significativa disminución de los precios relativos - y en muchos casos absolutos- de los bienes que consumen los estratos medios. También, como se analizará más adelante, contribuyeron a elevar la capacidad adquisitiva del hogar tanto la disminución del número de personas por hogar como la menor tasa de dependencia económica. ${ }^{14}$ Por otra parte, la baja del precio relativo de los bienes "durables" de consumo masificado alude también a su comparación con el mayor costo de la salud y de la educación, que ocupan una parte creciente del presupuesto familiar de los estratos medios. En este sentido, la incorporación del estrato bajo a las pautas de consumo del estrato medio es restringida y las "distancias" sociales se aprecian en muchos casos en la posibilidad de acceder a salud y educación privadas.

\section{Heterogeneidad de los estratos medios}

\section{a) Segmentación ex definitione}

De acuerdo con la definición adoptada para caracterizar a los estratos medios, es posible identificar tres subconjuntos de hogares. Ellos son:

i) Clase media "consistente", conformada por hogares de clase media cuyo principal proveedor de ingresos (PPIH) desempeña una ocupación no manual y donde el ingreso familiar total — suma del ingreso aportado por todos los miembros del hogar derivado del trabajo, del capital o de transferencias- fluctúa entre el equivalente a 4

\footnotetext{
${ }^{13}$ En el Brasil, Colombia, Costa Rica y el Perú la participación en el ingreso del $50 \%$ de los hogares que siguen al $40 \%$ más pobre bajó entre $1,5 \%$ y $4,5 \%$. En los demás países la participación de este segmento aumentó entre 1,5 y 2,5 puntos. En Honduras el incremento fue de 6 puntos porcentuales (CEPAL, 2008a, Anexo estadístico, cuadro 12).

${ }^{14}$ Debe destacarse que considerar al hogar como unidad de análisis registra mejor tales fenómenos que los análisis centrados en individuos.
}

líneas de pobreza, como nivel inferior, y el valor del percentil 95 de la distribución, como límite superior. ${ }^{15}$

ii) Clase media "inconsistente", integrada por hogares cuyo PPIH desempeña una ocupación manual, aunque el ingreso total familiar es propio de la clase media.

iii) Clase media "precaria". Un alto porcentaje de los asalariados no manuales tienen una inserción laboral inestable, con ingresos muy reducidos y a menudo sin contrato ni cobertura de seguridad social, muy similar a la que caracteriza a los asalariados manuales y por cuenta propia de baja calificación. Incluso hay pobreza absoluta entre los hogares del estrato medio. En los países con índices de pobreza más bajos, entre un $5 \%$ y un $9 \%$ de los hogares del estrato laboral medio se encontraban en esa situación en 2006-2007. En el Brasil y México constituían alrededor de una sexta parte, en tanto que en Colombia, el Perú y la República Dominicana representaban entre el $20 \%$ y el $30 \%$, llegando al $38 \%$ en Honduras. ${ }^{16}$

\section{b) Segmentación jerárquica}

A partir de la clasificación de la población según ocupación y sector o categoría del empleo se puede tener una idea de la magnitud relativa de los dos subestratos medios (superior y bajo). Aunque no es posible homogeneizar totalmente las clasificaciones de ocupación utilizadas en 1990 con las actuales, puede estimarse la magnitud relativa que actualmente tendrían esos dos estratos y destacar la diversidad de ocupaciones del estrato laboral medio.

En 7 de los 10 países considerados, en el estrato medio-bajo se concentran entre dos tercios y más de

\footnotetext{
${ }^{15} \mathrm{El}$ ingreso familiar total es diferente del ingreso per cápita del hogar, o sea, de la división del ingreso total entre el número de miembros del hogar que se utiliza en los estudios de pobreza. Asimismo, la unidad de análisis es el hogar y no uno de los individuos que lo integran, por ejemplo, el jefe de familia, como sucede en los estudios de movilidad social (véase León, Espíndola y Sembler, 2010).

${ }^{16}$ Sobre incidencia de la pobreza, véase CEPAL, Panorama Social de América Latina, diversas ediciones. Cabe recordar que este es un indicador en cuyo cálculo interviene el número de personas del hogar y en él se consideran el ingreso monetario de todos sus miembros ocupados y las demás corrientes de ingreso de los inactivos. Sin embargo, más de dos terceras partes del ingreso total de los hogares de cada estrato laboral (en este caso del estrato medio) son aportadas por el perceptor principal, de modo que el valor del indicador de pobreza capta en buena medida el bajo ingreso de los ocupados del estrato medio-bajo.
} 
tres cuartas partes del total de los hogares del total del estrato medio. Es la "puerta de entrada" a la clase media, a la que se accede mediante la credencial educativa secundaria o técnica. Este estrato medio-bajo también constituye la "zona de frontera" con el estrato bajo, al menos en términos de ingreso. Es entre las ocupaciones no manuales de menor jerarquía donde se dan con mayor frecuencia trayectorias individuales de movilidad ascendente, por la vía de las oportunidades de empleo, y descendente, derivadas de recesiones y crisis u otras contingencias (Kessler y Espinoza, 2007).

\section{c) Segmentación horizontal}

Las principales segmentaciones horizontales que pueden hallarse en la clase media son las relativas a la inserción laboral pública o privada y aquella referida a la ocupación asalariada o por cuenta propia. ${ }^{17}$

- Empleados del sector público o del sector privado

Diversos autores han argumentado que la expansión de la clase media en la región se produjo merced a la expansión del Estado y el aumento del empleo público. Dicho sector medio sería además portador de una cultura que habría dado soporte al imaginario de toda la "clase", basado en la preocupación por la educación y en determinado estilo de vida. Asimismo, habría sido afectado por las reformas que redujeron el papel del Estado y disminuyeron consecuentemente el empleo público (Klein y Tokman, 2000; Torche, 2006).

Esta hipótesis no se ha podido confirmar en la presente investigación. Cabe reconocer que son escasos los países seleccionados en que ha podido compararse el peso del empleo público en 1990 con un año reciente. En cuatro casos (la Argentina, el Brasil, Chile y México) la información correspondiente al año base no discriminó entre empleados públicos y privados. En los casos en que fue posible efectuar dicha comparación para los principales perceptores de ingreso y para el conjunto de la población ocupada, se aprecia que el empleo público de clase media se mantuvo relativamente en Honduras, en el Perú y en Colombia; se redujo en Costa Rica y Panamá y creció solamente en la República Dominicana (véanse los cuadros 6 y 7 ).

\footnotetext{
17 Trabajador independiente es el no asalariado. Incluye tanto a empleadores como a trabajadores por cuenta propia (que no emplean fuerza de trabajo). La distinción entre asalariados y no asalariados excluye a los empleadores (cualquiera sea el número de trabajadores que contraten), que forman parte del estrato alto de acuerdo con la definición de estratos laborales utilizada.
}

Para la Argentina, el Brasil y Chile existen datos correspondientes al año final de la serie utilizada, así como otros antecedentes que permiten señalar la tendencia. Para el Brasil hay información de registros administrativos que indican que durante los años noventa se mantuvo la proporción del empleo público dentro del empleo total, aunque cambió su distribución, disminuyendo en los niveles federal y estadual y expandiéndose en el municipal (Pessoa de Carvalho Filho, Eneuton Dornellas, 2002). Por ello resulta plausible sostener que el empleo público en ese país se mantuvo en torno del 24\% del total de ocupados. En Chile, las encuestas de empleo del Instituto Nacional de Estadísticas (INE) indican que entre 1990 y 2000 los asalariados públicos aumentaron como proporción del empleo total (de 6,9\% a $7,4 \%$ ), lo que habría significado una leve baja dentro de los ocupados de sectores medios: de $22 \%$ a $20 \%$ (León y Martínez, 2007; Torche y Wormald, 2007). ${ }^{18}$ Sin embargo, desde mediados de la década pasada los asalariados públicos se incrementaron en un $35 \%$, superando el crecimiento de los asalariados del sector privado (22\%) y de los trabajadores por cuenta propia (20\%) (Méndez, 2009). ${ }^{19}$

En la Argentina hubo un leve aumento en el total de empleados públicos entre 1999 y 2006 (de 15,5\% a $16,2 \%$ ), después de alcanzar su nivel más alto en 2002 $(21,7 \%)$. En esa cifra se incluye a los ocupados en los programas gubernamentales de generación de empleo. ${ }^{20}$ En México, en los datos correspondientes a los años 1994, 1996, 1998 y 2002 se aprecia una leve baja y luego un repunte para mantenerse entre un $11 \%$ y un $12 \%$ durante el período (CEPAL, 2008a). ${ }^{21}$

En definitiva, en estos países no hubo una pérdida importante de participación del sector público como empleador de las clases medias. Sin embargo, esto nada dice respecto de una posible pérdida de estatus simbólico y socioeconómico de ese tipo de empleo. En todo caso, en los últimos años los asalariados públicos de la mayoría de los países considerados han logrado mejoras

\footnotetext{
${ }^{18}$ Los datos sobre Chile se obtuvieron a partir de la Encuesta de Caracterización Socioeconómica Nacional (CASEN 1990 y 2006)) que presenta ventajas desde el punto de vista de la medición del ingreso. Las encuestas de empleo del Instituto Nacional de Estadísticas (INE), en cambio, permiten la comparación en el tiempo de las mediciones del nivel y estructura del empleo.

${ }^{19}$ Los aumentos porcentuales de las tres categorías se refieren al período 1996-2006. Véase Méndez, 2009, cuadro 5.

${ }^{20}$ El Programa Jefes de Hogar comenzó a gestionarse a principios de 2002 y generó más de dos millones de plazas para desocupados. Cifra publicada por el Ministerio de Trabajo, Empleo y Seguridad Social, http:://www.trabajo.gov.ar.

${ }^{21}$ Véase cepal (2008a), Anexo estadístico, cuadro 17.
} 
CUADRO 6

\section{América Latina (10 países): distribución de los principales perceptores de ingreso} del hogar, según categoría de ocupación, alrededor de 1990 y 2007

\begin{tabular}{|c|c|c|c|c|c|c|c|c|c|c|}
\hline \multirow{2}{*}{ Estrato medio ${ }^{b}$} & \multicolumn{2}{|c|}{ Argentina $^{\mathrm{a}}$} & \multicolumn{2}{|c|}{ Brasil } & \multicolumn{2}{|c|}{ Chile } & \multicolumn{2}{|c|}{ Colombia } & \multicolumn{2}{|c|}{ Costa Rica } \\
\hline & 1990 & 2006 & 1990 & 2007 & 1990 & 2006 & 1991 & 2005 & 1990 & 2007 \\
\hline Asalariado público & $\ldots$ & 20 & $\ldots$ & 24 & $\ldots$ & 14 & 16 & 18 & 40 & 31 \\
\hline Asalariado privado & 74 & 58 & 66 & 53 & 66 & 63 & 39 & 42 & 40 & 58 \\
\hline Por cuenta propia & 26 & 22 & 34 & 24 & 34 & 23 & 44 & 40 & 20 & 11 \\
\hline Total & 100 & 100 & 100 & 100 & 100 & 100 & 100 & 100 & 100 & 100 \\
\hline \multicolumn{11}{|l|}{ Total $^{\mathrm{c}}$} \\
\hline Asalariado público & $\ldots$ & 12 & $\ldots$ & 13 & $\ldots$ & 11 & 8 & 8 & 19 & 16 \\
\hline Asalariado privado & 66 & 62 & 63 & 52 & 69 & 63 & 46 & 42 & 46 & 56 \\
\hline Por cuenta propia & 26 & 21 & 29 & 30 & 27 & 22 & 41 & 42 & 27 & 19 \\
\hline Empleador & 8 & 5 & 8 & 6 & 4 & 4 & 4 & 8 & 9 & 10 \\
\hline Total & 100 & 100 & 100 & 100 & 100 & 100 & 100 & 100 & 100 & 100 \\
\hline \multirow[t]{2}{*}{ Estrato medio ${ }^{\mathrm{b}}$} & \multicolumn{2}{|c|}{ Honduras } & \multicolumn{2}{|c|}{ México } & \multicolumn{2}{|c|}{ Panamá } & \multicolumn{2}{|c|}{ Perú } & \multicolumn{2}{|c|}{$\begin{array}{l}\text { República } \\
\text { Dominicana }\end{array}$} \\
\hline & 1990 & 2007 & 1989 & 2006 & 1991 & 2007 & 1997 & 2003 & 1997 & 2007 \\
\hline Asalariado público & 24 & 24 & $\ldots$ & $\ldots$ & 47 & 37 & 26 & 29 & 20 & 23 \\
\hline Asalariado privado & 32 & 44 & 73 & 70 & 39 & 49 & 40 & 40 & 43 & 44 \\
\hline Por cuenta propia & 44 & 32 & 27 & 30 & 14 & 14 & 33 & 31 & 38 & 33 \\
\hline Total & 100 & 100 & 100 & 100 & 100 & 100 & 100 & 100 & 100 & 100 \\
\hline \multicolumn{11}{|l|}{ Total $^{\mathrm{c}}$} \\
\hline Asalariado público & 9 & 9 & $\ldots$ & $\ldots$ & 25 & 18 & 10 & 11 & 12 & 12 \\
\hline Asalariado privado & 36 & 45 & 65 & 69 & 35 & 47 & 33 & 33 & 37 & 34 \\
\hline Por cuenta propia & 53 & 43 & 30 & 25 & 34 & 30 & 47 & 47 & 45 & 48 \\
\hline Empleador & 2 & 3 & 5 & 6 & 5 & 5 & 10 & 9 & 6 & 6 \\
\hline Total & 100 & 100 & 100 & 100 & 100 & 100 & 100 & 100 & 100 & 100 \\
\hline
\end{tabular}

Fuente: Comisión Económica para América Latina y el Caribe (CEPAL), sobre la base de tabulaciones especiales de las encuestas de hogares de los respectivos países.

a Gran Buenos Aires.

b Se refiere a perceptores principales de ingreso del estrato laboral medio. Los empleadores integran el estrato laboral alto.

c Se refiere al total de perceptores principales de ingreso (del estrato laboral alto, medio y bajo).

...:Los datos que faltan no están disponibles por separado. En estos casos los asalariados públicos se incluyen en la categoría de asalariados privados. 
CUADRO 7

\section{América Latina (10 países): distribución del total de ocupados,} según categoría de ocupación, alrededor de 1990 y 2007

\begin{tabular}{|c|c|c|c|c|c|c|c|c|c|c|}
\hline \multirow{2}{*}{ Estrato medio ${ }^{b}$} & \multicolumn{2}{|c|}{ Argentina $^{\mathrm{a}}$} & \multicolumn{2}{|c|}{ Brasil } & \multicolumn{2}{|c|}{ Chile } & \multicolumn{2}{|c|}{ Colombia } & \multicolumn{2}{|c|}{ Costa Rica } \\
\hline & 1990 & 2006 & 1990 & 2007 & 1990 & 2006 & 1991 & 2005 & 1990 & 2007 \\
\hline Asalariado público & $\ldots$ & 18 & $\ldots$ & 19 & $\ldots$ & 13 & 13 & 13 & 32 & 27 \\
\hline Asalariado privado & 74 & 61 & 71 & 56 & 71 & 65 & 51 & 46 & 46 & 60 \\
\hline Por cuenta propia & 25 & 20 & 28 & 24 & 29 & 21 & 36 & 40 & 21 & 13 \\
\hline Empleador & 1 & 1 & 1 & 1 & 0 & 0 & 1 & 1 & 1 & 1 \\
\hline Total & 100 & 100 & 100 & 100 & 100 & 100 & 100 & 100 & 100 & 100 \\
\hline \multicolumn{11}{|l|}{ Total $^{\mathrm{c}}$} \\
\hline Asalariado público & $\ldots$ & 12 & $\ldots$ & 12 & $\ldots$ & 10 & 7 & 6 & 16 & 14 \\
\hline Asalariado privado & 70 & 65 & 66 & 54 & 73 & 66 & 53 & 45 & 52 & 60 \\
\hline Por cuenta propia & 25 & 19 & 29 & 31 & 24 & 21 & 38 & 44 & 26 & 18 \\
\hline Empleador & 5 & 4 & 5 & 4 & 3 & 3 & 3 & 5 & 6 & 7 \\
\hline Total & 100 & 100 & 100 & 100 & 100 & 100 & 100 & 100 & 100 & 100 \\
\hline \multirow[t]{2}{*}{ Estrato medio ${ }^{\mathrm{b}}$} & \multicolumn{2}{|c|}{ Honduras } & \multicolumn{2}{|c|}{ México } & \multicolumn{2}{|c|}{ Panamá } & \multicolumn{2}{|c|}{ Perú } & \multicolumn{2}{|c|}{$\begin{array}{c}\text { República } \\
\text { Dominicana }\end{array}$} \\
\hline & 1990 & 2007 & 1989 & 2006 & 1991 & 2007 & 1997 & 2003 & 1997 & 2007 \\
\hline Asalariado público & 19 & 19 & $\ldots$ & $\ldots$ & 40 & 30 & 20 & 20 & 17 & 20 \\
\hline Asalariado privado & 38 & 44 & 75 & 69 & 46 & 54 & 43 & 42 & 48 & 45 \\
\hline Por cuenta propia & 43 & 36 & 25 & 30 & 14 & 17 & 36 & 37 & 34 & 34 \\
\hline Empleador & 0 & 1 & 0 & 1 & 0 & 0 & 1 & 1 & 0 & 1 \\
\hline Total & 100 & 100 & 100 & 100 & 100 & 100 & 100 & 100 & 100 & 100 \\
\hline \multicolumn{11}{|l|}{ Total $^{\mathrm{c}}$} \\
\hline Asalariado público & 7 & 7 & $\ldots$ & $\ldots$ & 23 & 15 & 9 & 8 & 11 & 12 \\
\hline Asalariado privado & 38 & 44 & 67 & 68 & 41 & 50 & 35 & 33 & 45 & 37 \\
\hline Por cuenta propia & 54 & 46 & 30 & 28 & 33 & 31 & 51 & 55 & 40 & 47 \\
\hline Empleador & 1 & 2 & 3 & 4 & 3 & 3 & 5 & 5 & 4 & 4 \\
\hline Total & 100 & 100 & 100 & 100 & 100 & 100 & 100 & 100 & 100 & 100 \\
\hline
\end{tabular}

Fuente: Comisión Económica para América Latina y el Caribe (CEPAL), sobre la base de tabulaciones especiales de las encuestas de hogares de los respectivos países.

a Gran Buenos Aires.

b Se refiere al total de ocupados en hogares del estrato laboral medio.

c Se refiere al total de ocupados (en hogares del estrato laboral alto, medio y bajo).

...: Los datos que faltan no están disponibles por separado. En estos casos los asalariados públicos se incluyen en la categoría de asalariados privados. 
de remuneraciones superiores a las de los asalariados privados (CEPAL. 2008a). ${ }^{22}$

- Asalariados y trabajadores independientes

Una tendencia más clara de reestructuración se produjo en las ocupaciones del sector privado. Hubo un incremento del empleo asalariado y una reducción del trabajo independiente o por cuenta propia. Esto parece oponerse a la idea de una clase media crecientemente integrada por profesionales y técnicos calificados, que se desempeñan de manera independiente como autoempleados y pequeños empresarios. En los países analizados, con excepción de México y Panamá, perdió representación el autoempleo en el sector medio. Ello fue más marcado entre los PPIH que entre el total de ocupados de ese estrato (véanse los cuadros 6 y 7). ${ }^{23}$

22 Véase CEPAL (2008a), Anexo estadístico, cuadro 21.

${ }^{23}$ Se trata de una disminución del autoempleo en la gran mayoría de los países. No hay una desagregación de los datos por grupos de edades. De haberlo, podría observarse si la reducción del autoempleo se da también entre los jóvenes que ingresan al mercado de trabajo. Asimismo, las características ocupacionales de la población se refieren al empleo principal. Es frecuente que asalariados en su empleo
La mayor participación laboral femenina fue decisiva para la expansión del estrato medio. Entre 1990 y 2007 esa tasa se acrecentó de modo significativo. En 7 de los 10 países la tasa de actividad económica de las mujeres se elevó entre 6 y 14 puntos porcentuales. El incremento fue mayor en el Brasil, Chile, Costa Rica y México, países en que se registró el mayor aumento del estrato medio. ${ }^{24}$ La expansión de la participación femenina se generó con especial dinamismo entre las mujeres de mayor nivel educacional (CEPAL, 2008a), que se incorporaron a ocupaciones en el comercio y los servicios (oficinistas, secretarias, dependientas de tiendas y supermercados y trabajadoras de los servicios de salud). Las tasas de participación de las mujeres con educación superior (profesionales que integran el estrato medio-alto) también crecieron, pero relativamente menos pues ya eran bastante elevadas a comienzo de los años noventa.

principal se desempeñen como trabajadores independientes en su actividad económica secundaria.

${ }^{24}$ Véase cepal (2008a), Anexo estadístico, cuadro 16.

\section{IV}

\section{Factores determinantes de los cambios}

\section{El tamaño importa}

El verdadero impacto que el crecimiento provoca en las pautas de consumo no se aprecia adecuadamente en el análisis porcentual de los datos. Surge más claramente al considerar los valores absolutos, al igual que la magnitud y el ritmo de crecimiento de la población, especialmente en centros urbanos o en determinadas zonas de las grandes ciudades.

Los hogares de clase media crecieron en 56 millones en el universo considerado de 10 países que representan el $80 \%$ de la población latinoamericana. Ello implica una notable ampliación del mercado consumidor. En el país más grande de la región, el Brasil, el número de personas que viven en hogares de estrato medio aumentó de 23 millones en 1990 a 61 millones en 2007. El número de hogares del estrato medio se duplicó con creces (de 9,3 millones en 1990 a 20,8 millones en 2007) y estos pasaron a representar del $36 \%$ al $46 \%$ del total de hogares. En un período similar, en Chile los hogares medios crecieron cerca de 1,1 millones, casi duplicando la cifra de 1,2 millones estimada para el año inicial. En la Argentina, no obstante haberse reducido la proporción de hogares medios (del 56\% al 52\%), su número absoluto aumentó en cerca de medio millón, incremento que fue incluso mayor que el de personas (440 mil) debido a la fuerte disminución del tamaño de los hogares de ese estrato. El gran número y la concentración espacial de los hogares del estrato medio promueven el efecto demostración en el conjunto de la sociedad, influyen en los hábitos de consumo y generan, por consiguiente, un extendido sentimiento de pertenencia a ese estrato.

La disminución del número de personas por hogar fue generalizada aunque de magnitud distinta, según el nivel de fecundidad prevaleciente en cada país hace 15 años, las condiciones socioeconómicas y las pautas culturales propias de los diferentes estratos sociales (CEPAL, 2004). A comienzos de los años noventa, en los países con hogares más extensos la merma del número de miembros probablemente se explica en mayor medida 
por la menor fecundidad (casos de México y Honduras), mientras que en aquellos otros con tasas de fecundidad más bajas la reducción se vincula más a la mayor proporción de hogares unipersonales o de parejas sin hijos (el caso de la Argentina).

La tasa de dependencia, en que se combinan el efecto de la disminución del número de personas y el aumento del número de ocupados en los hogares, se redujo tanto en el estrato medio (de 2,7\% a 2,1\%) como en el bajo (de 2,8\% a 2,4\%). En ese proceso jugaron un papel crucial tanto la retracción de la fecundidad como la ampliación de la participación laboral de las mujeres — especialmente las de mayor nivel de educación-y la modificación de los tipos de familia. El Brasil y México son los dos países que registran el mayor incremento en la tasa de participación de las mujeres en la actividad económica durante el período examinado. En el Brasil esa tasa se elevó del $44 \%$ al $58 \%$ y en México del $30 \%$ al $48 \% .{ }^{25}$

\section{Crecen los sectores medios}

En el conjunto de los países analizados crece el número de hogares de clase media y la proporción de ellos en relación con el total de hogares. Las excepciones son la Argentina, donde decayeron del 56\% al 52\%, y Colombia, donde la proporción se mantuvo estable. En aquellos países con mayor nivel de desarrollo el estrato medio tiene mayor tamaño. Mientras que en Honduras solo abarca al $25 \%$ de los hogares, en la Argentina o Chile incluye a la mitad. En este último país, el $40 \%$ de los hogares eran de clase media en 1990 y hoy lo son el $52 \%$. Asimismo, debe hacerse notar que se acrecienta el ingreso familiar de la clase baja, definida por la ocupación manual del PPIH. Esto provocó el desplazamiento de ese sector de hogares a un tramo de ingreso más alto, es decir, del estrato de hasta 5.000 dólares al estrato cuyo ingreso anual fluctúa entre 5.000 dólares y 15.000 dólares (por familia).

Hay un importante incremento de hogares con ingresos medios. En la Argentina, Chile y Panamá ese incremento provino en gran parte de la mejora de los hogares del estrato laboral bajo. En el Brasil, Costa Rica, Honduras y México el aumento de esos hogares fue menor pero significativo, especialmente debido a la expansión del número total de hogares de estratos sociales medios (ESM) (véase la última columna del cuadro 8).

\footnotetext{
25 Véase CEPAL (2008a, Anexo estadístico, cuadro 16).
}

\begin{tabular}{|c|c|c|c|c|c|}
\hline & $\begin{array}{l}\text { Améric } \\
\text { de estr } \\
\text { alredec }\end{array}$ & $\begin{array}{l}\text { Latina } \\
\text { tos soc } \\
\text { or de } 19\end{array}$ & $\begin{array}{l}10 \text { países): } h \\
\text { ales medios, } \\
0 \text { y } 2007\end{array}$ & ogares & \\
\hline País & Año & $\begin{array}{l}\text { Con } \\
\text { ingreso } \\
\text { medio }^{\mathrm{a}}\end{array}$ & $\begin{array}{c}\text { De estrato } \\
\text { medio con } \\
\text { ingreso bajo }\end{array}$ & $\begin{array}{c}\text { Estratos } \\
\text { sociales } \\
\text { medios }\end{array}$ & $\begin{array}{l}\text { Total } \\
\text { de } \\
\text { hogares }\end{array}$ \\
\hline & & & porcentajes $^{c}$ & & (miles) \\
\hline Argentina $^{\mathrm{d}}$ & 1990 & 25 & 42 & 67 & 2181 \\
\hline & 2006 & 54 & 20 & 74 & 3134 \\
\hline Brasil & 1990 & 24 & 22 & 46 & 15825 \\
\hline & 2007 & 26 & 27 & 53 & 33454 \\
\hline Chile & 1990 & 31 & 23 & 54 & 1702 \\
\hline & 2006 & 54 & 16 & 70 & 3645 \\
\hline Colombia & 1991 & 23 & 20 & 43 & 3012 \\
\hline & 2005 & 23 & 16 & 39 & 4674 \\
\hline Costa Rica & 1990 & 45 & 13 & 58 & 320 \\
\hline & 2007 & 50 & 12 & 62 & 834 \\
\hline Honduras & 1990 & 9 & 12 & 21 & 170 \\
\hline & 2007 & 11 & 17 & 28 & 544 \\
\hline México & 1989 & 23 & 21 & 44 & 6940 \\
\hline & 2006 & 26 & 22 & 48 & 14160 \\
\hline Panamá & 1991 & 39 & 12 & 51 & 260 \\
\hline & 2007 & 47 & 12 & 59 & 610 \\
\hline Perú & 1997 & 16 & 16 & 32 & 1665 \\
\hline & 2003 & 14 & 18 & 32 & 2248 \\
\hline República & 1997 & 28 & 11 & 39 & 633 \\
\hline Dominicana & 2007 & 20 & 18 & 38 & 1081 \\
\hline
\end{tabular}

Fuente: Comisión Económica para América Latina y el Caribe (CEPAL), sobre la base de tabulaciones especiales de encuestas de hogares de los países.

a Hogares en que el ingreso del PPIH supera el valor correspondiente a cuatro veces la línea de pobreza per cápita urbana y es inferior al valor del percentil 95.

b Se refiere a hogares de estrato laboral medio en que el PPIH tiene un ingreso menor o igual a cuatro veces el valor de la línea de pobreza per cápita urbana.

c Porcentajes con respecto al total de hogares del país.

d Gran Buenos Aires.

Cabe destacar, empero, que una proporción relativamente alta del total de hogares de estrato medio tiene ingresos insuficientes. En el Brasil alcanza al 51\%, mientras que en Chile se redujo del $43 \%$ al $23 \%$ el porcentaje del total de hogares de los ESM con ingresos bajos. ${ }^{26} \mathrm{Un}$

\footnotetext{
${ }^{26}$ Hogares en que el ingreso del principal perceptor es inferior a cuatro veces el valor de la línea de pobreza por miembro del hogar. Los
} 
cambio similar se produjo en la Argentina, aunque el aumento de la gravitación del conjunto de hogares de los ESM fue menor que en Chile. En los demás países estos cambios en la composición de los ESM fueron de menor significación.

Al delimitar los ESM mediante la combinación de inserción laboral e ingreso surge un amplio conjunto de hogares cercano o superior al 50\% del total en la Argentina, el Brasil, Chile, Costa Rica, México y Panamá. Estas cifras otorgan sustento a la visión que surge de diversos sondeos y encuestas de opinión, según los cuales una proporción muy alta de los entrevistados afirman pertenecer a la "clase media".

\section{Aumenta el capital educacional, pero se incrementa la devaluación educativa}

En las dos últimas décadas hubo en la región una acelerada expansión de los niveles de escolaridad. El engrosamiento de las tasas de matrícula y de graduación en todos los niveles produjo un cambio muy significativo del perfil educacional de la población económicamente activa. El capital educacional sigue siendo crucial para incorporarse a los estratos medios, sea en empleos no manuales rutinarios —que requieren la certificación del segundo ciclo de la educación media o secundaria-, sea con un título profesional de la educación superior para las ocupaciones típicas del estrato medio-alto.

Tiende a generalizarse el que las nuevas generaciones completen el ciclo secundario. En 1990, entre el 30\% y el $40 \%$ de los PPIH de clase media habían alcanzado ese nivel educativo. En la actualidad, entre el 50\% y el 70\% de los PPIH están graduados, variando según los países. En la Argentina, asimismo, en el pasado completaban la formación técnica el $31 \%$ de los PPIH, mientras que hoy lo hacen el 47\%. A su vez, en el Brasil la proporción de los PPIH que alcanzaron esa formación pasó del $28 \%$ al $48 \%$, y en Chile, del $41 \%$ al $57 \%$. De igual modo, se aprecia que el $83 \%$ de los jóvenes de clase media ingresan al mercado laboral habiendo concluido por lo menos sus estudios secundarios o incluso con un mayor nivel educacional.

El incremento de la educación también se produjo entre los ocupados del estrato bajo, pero solo aquellos que alcanzaron la formación secundaria completa tienen una alta probabilidad de acceder a empleos no manuales. Quienes ya están en el mercado de trabajo con formación

porcentajes mencionados corresponden al cuociente entre la segunda y la tercera columnas del cuadro 8, multiplicado por 100 . incompleta no obtienen mejoras salariales relevantes, aunque incorporen algunos años suplementarios de educación. En cambio, el ingreso se acrecienta en forma acelerada para los que han completado el ciclo secundario y suman posteriormente años de estudio adicionales. $^{27}$

La tendencia a la generalización del ciclo completo de educación secundaria trajo consigo una devaluación relativa de la educación, que se manifiesta en un distanciamiento (o rezago) progresivo de las remuneraciones que reciben quienes logran ese nivel educativo en comparación con los que terminan la educación superior, lo que se observa con claridad entre los jóvenes (CEPAL, 2008b). ${ }^{28}$

$\mathrm{El}$ aumento de miembros del estrato bajo (manuales) con mayor nivel educacional y de ingreso, por una parte, y de amplias capas del estrato medio-bajo (no manuales) con al menos educación secundaria completa que se emplean con ingresos relativamente bajos, por otra, han generado una homogeneización de los ingresos entre ambos estratos y una creciente disociación entre tipo de ocupación e ingreso.

Es importante tener en cuenta que, en términos relativos, las remuneraciones de quienes hoy completan el ciclo secundario son menores que las que obtenían en el pasado quienes llegaban al mercado laboral con ese nivel educativo. Tradicionalmente, la conclusión de la educación secundaria constituía el umbral educativo de la clase media, por cuanto se entendía que ello permitía una mayor apropiación de los códigos culturales de la modernidad y por tanto facilitaba el acceso al trabajo "intelectual". La masificación del egreso de dicho nivel desdibujaría ese sello de distinción.

Puede verse el vaso "medio lleno" al considerar la gran proporción de jóvenes con educación secundaria completa. Pero también se lo puede ver "medio vacío" si se enfatiza la pérdida de estatus, tanto simbólico como material, que hoy afecta a ese logro. Cabe recordar, además, que la práctica de aplicar pruebas estandarizadas que miden los aprendizajes efectivos y su calidad muestra sistemáticamente déficits generalizados, lo que agrava la degradación simbólica de lo alcanzado en años de escolaridad.

No obstante, hay segmentaciones importantes en cuanto al logro educacional y el tipo de empleo al que acceden estas nuevas cohortes. En Chile, por ejemplo, pese a la rápida expansión de la cobertura educativa,

\footnotetext{
27 Véase CEPAL (2008b, cap. IV, págs. 141-144).

${ }^{28}$ Este factor ha contribuido a ampliar las brechas de remuneraciones y a mantener un elevado nivel de desigualdad en la distribución del ingreso en la región.
} 
se mantienen diferencias en los perfiles educacionales de los jóvenes según su categoría social. Así, más del $83 \%$ de quienes pertenecen a sectores medios llegan al mercado laboral con 12 años o más de escolaridad, mientras que solo lo hacen el $43 \%$ entre los de clase obrera (León y Martínez, 2007). Por otra parte, llama la atención la vertiginosa expansión de la matrícula secundaria durante el último decenio y la movilidad social que entraña: el $70 \%$ de los estudiantes universitarios chilenos constituyen la primera generación de su familia que cursa estudios de este nivel.

\section{Pierde relevancia el corte de ingresos entre ocupaciones manuales y no manuales}

Hay una tendencia a la homogeneización de los ingresos percibidos por personas de clase media y clase baja. Ello se debe a que hay muchos empleos no manuales de baja calidad, al mismo tiempo que existen ocupaciones manuales bien retribuidas. Hay "trabajadores manuales [que] disponen de más conocimientos que muchos trabajadores de clase media, obtienen mayores ingresos y generan aspiraciones más definidas de movilidad social. En general... la condición de trabajador manual no excluye una eventual pertenencia a la clase media, dependiendo de la industria, la localización y la cultura del entorno laboral y social. Los trabajadores competitivos tienden a generar unas expectativas, una visión del mundo y unas demandas políticas distintas a las que generan los trabajadores no competitivos" (Mora y Araujo, 2008).

\section{Penetración de los bienes de estrato medio y efecto de demostración}

El proceso mencionado amplió notablemente la demanda de bienes de consumo (productos eléctricos y electrónicos, celulares, internet, automóviles, y otros) haciendo más "visible" la penetración de tales bienes. Esto tal vez acrecentó su valoración en la población del estrato bajo y provocó la percepción de que su adquisición constituye la principal vía de integración social, mientras que no poseerlos se percibe como una forma de exclusión.

La Argentina constituye un caso especial. La crisis de 2001-2002 acarreó, entre otras consecuencias negativas, un elevado desempleo abierto y la reducción de los ingresos familiares. Sin embargo, la reanudación del crecimiento a partir de 2003 y hasta avanzado el año 2008 permitió que —en promedio— los hogares de los estratos medio y bajo recuperaran los niveles de ingreso previos a la crisis. Por ello, en la comparación de largo plazo ("punta a punta") no se aprecia un deterioro marcado del ingreso de los estratos laborales medios. En el cuadro 9 se resumen los cambios en la distribución de los hogares según tramos de ingreso en

CUADRO 9

Argentina (Gran Buenos Aires, tres períodos): distribución de los hogares según tramos de ingreso familiar ${ }^{\mathrm{a}} \mathrm{y}$ estrato laboral ${ }^{\mathrm{b}}$ (En porcentajes)

\begin{tabular}{|c|c|c|c|c|c|c|}
\hline & Estrato medio & Estrato bajo & Total & Estrato medio & Estrato bajo & Total \\
\hline & \multicolumn{3}{|c|}{1990} & \multicolumn{3}{|c|}{1999} \\
\hline Hasta 5000 & 5 & 15 & 11 & 5 & 6 & 5 \\
\hline 5001 a 15000 & 33 & 34 & 32 & 28 & 41 & 32 \\
\hline \multirow[t]{2}{*}{ Más de 15000} & 63 & 51 & 58 & 67 & 53 & 62 \\
\hline & \multicolumn{3}{|c|}{1999} & \multicolumn{3}{|c|}{2002} \\
\hline Hasta 5000 & 5 & 6 & 5 & 16 & 26 & 20 \\
\hline 5001 a 15000 & 28 & 41 & 32 & 39 & 49 & 42 \\
\hline \multirow[t]{2}{*}{ Más de 15000} & 67 & 53 & 62 & 46 & 26 & 39 \\
\hline & \multicolumn{3}{|c|}{2002} & \multicolumn{3}{|c|}{2006} \\
\hline Hasta 5000 & 16 & 26 & 20 & 3 & 9 & 6 \\
\hline 5001 a 15000 & 39 & 49 & 42 & 31 & 37 & 32 \\
\hline Más de 15000 & 46 & 26 & 39 & 66 & 54 & 62 \\
\hline
\end{tabular}

Fuente: CEPAL, sobre la base de tabulaciones especiales de encuestas de hogares de los países.

a Los tramos de ingreso corresponden a ingreso anual, en dólares de poder adquisitivo de paridad del año 2000.

b Por efecto de redondeo algunas columnas no suman $100 \%$. 
tres períodos (1990-1999; 1999-2002 y 2002-2006) en el Gran Buenos Aires. Entre 1999 y 2002, el porcentaje de hogares del estrato medio con ingresos anuales inferiores a 5.000 dólares se triplicó, y se cuadruplicó entre los hogares del estrato laboral bajo. ${ }^{29} \mathrm{El}$ deterioro fue importante, según se aprecia en el deslizamiento hacia abajo de todos los hogares en la escala del ingreso (véanse la tercera y la sexta columnas del cuadro 9). Sin embargo, durante la recuperación, el crecimiento del ingreso benefició más a los hogares del estrato bajo (72\%) que a los del medio (39\%), reduciendo marcadamente la disparidad de ingresos entre ambos. ${ }^{30}$ Esto indica que también en este país se habría dado una ampliación del estrato medio por la vía del aumento de la capacidad de consumo de los hogares del estrato bajo, aunque sería un fenómeno más reciente, como también lo es en el Brasil.

${ }^{29}$ Cabe recordar que en el término "estrato laboral" se incluye a los principales perceptores de ingreso de los hogares, sean estos ocupados o inactivos.

${ }^{30}$ En 2002 y 2006, las cifras sobre ingreso promedio mensual de los hogares del estrato medio alcanzan a 1.855 y 2.574 dólares mensuales, respectivamente. Las correspondientes al estrato bajo se elevan a 1.067 y 1.835 dólares mensuales del año 2000 medidos en paridad de poder adquisitivo.

\section{Competitivos y no competitivos}

La globalización y la interconexión mundial afectan a las clases medias al convertirse la competitividad en un elemento central, en el doble sentido de tener las habilidades necesarias y de poseer espíritu competitivo y capacidad de asumir riesgos. Debido a su obsolescencia tecnológica y educacional, los no competitivos carecen de una preparación adecuada para enfrentar un mercado laboral cambiante, y por ello enfrentan el riesgo del desempleo y sus salarios siguen una tendencia a la baja. Por otra parte, en la medida en que la competitividad se vincula a la incesante actualización de información y conocimiento, al cambio de destrezas y a la adaptación a nuevas formas de organización, ella impone tensiones y marca nuevas líneas divisorias entre perdedores y ganadores. Todo ello fragiliza a una parte de la clase media cuyas especializaciones o formas de trabajar pierden demanda en los mercados laborales, y en particular a quienes por edad o nivel educativo tienen más problemas para reciclarse. La sindicalización puede ayudar a mantener el nivel de salarios e incluso a elevarlo, pero sobre todo es útil para defender las condiciones laborales y sostener la estabilidad, por cuanto eleva los costos de aquella empresa que pretenda reducir el número de trabajadores (Mora y Araujo, 2008).

\section{$\mathrm{V}$ \\ ¿Qué es ser de clase media?}

Conviene reflexionar sobre las diferencias que existen entre el volumen de la clase media medido a través de dimensiones "objetivas" y la proporción muy superior de quienes se autoidentifican con esa clase en los estudios demoscópicos.

\section{El papel del consumo en la identidad de clase media: el lado eufórico}

La masificación del crédito de consumo ha implicado un mayor acceso a bienes durables y a ciertos servicios. Según datos de la CEPAL, el Banco Interamericano de Desarrollo (BID) y el Banco Mundial, entre 1990 y el año 2006 el crédito doméstico creció del 30\% al 55\% del PIB en la región, siendo mayor la expansión en el
Mercosur (Matesanz y Palma, 2008), lo que favoreció especialmente a los sectores medios y bajos. El incremento del crédito en los sectores altos acompaña al aumento del producto. Lo que aquí se observa es que el crédito se expandió vertiginosamente en relación con el producto, sugiriendo que alcanzó a otros sectores de la población.

El caso del Brasil es elocuente. El crecimiento económico contribuyó al incremento de las operaciones de crédito, que se decuplicaron entre 1999 y 2007 junto con el abaratamiento de su costo. La tasa de interés, aunque siguió siendo muy elevada, bajó del 90,2\% en 1999 al 43,9\% en 2007. Esta facilitación del crédito reforzó el gran mercado de consumo de las clases populares, que llegó más allá de la denominada "clase 
C", abarcando también a los hogares que forman parte de los estratos D y E, los más bajos de la estratificación (Oliveira, 2010). ${ }^{31}$

A lo anterior se agrega el advenimiento de la sociedad de bajo costo (Gaggi y Narduzi, 2007). La incorporación de grandes masas al consumo obedece a una combinación de factores: la apertura del comercio internacional, la deslocalización de la fabricación de productos y partes en función del abaratamiento de los factores de producción, la rápida difusión de nuevas tecnologías en la producción masiva y los aumentos de escala con la incorporación de nuevos consumidores. Artículos electrónicos, computadoras, vestimenta, paquetes de viajes, diversos artículos del hogar, teléfonos celulares, y otros, forman parte de un mercado cada vez más amplio y dinámico de compradores ávidos de consumo y de acceso a financiamiento.

La combinación de una mayor capacidad de endeudamiento — mediante tarjetas de crédito—y de más consumo, así como el desarrollo de grandes empresas orientadas a los productos masivos de bajo costo, contribuyeron al surgimiento de una nueva clase media.

Hoy la definición de las identidades colectivas y la distinción entre los grupos está dada por el contenido simbólico del consumo, que expresa significados compartidos y contribuye a reforzar las marcas de identidad y de posición social. En otras palabras, el tipo de consumo emite "señales" que permiten identificar a un consumidor específico como perteneciente a un determinado estrato socioeconómico. En este marco, la capacidad de consumir resulta central para la formación de la identidad de clase media y su variabilidad redefine los bienes que en cada momento pasan a cumplir un papel diferenciador ligado simbólicamente a esa actividad humana (Oliveira, 2010).

Sin duda, ese papel del consumo como identificador de un estilo de vida y de la pertenencia a un agregado o clase social siempre ha existido. Pero la irrupción de la sociedad de bajo costo tiende a generar -más allá de una clase alta, afluente y sofisticada- otro escalón masificado, de renta media-baja, cuyos miembros pueden acceder a bienes y servicios que antes estaban reservados a los sectores de mayores ingresos (Gaggi y Narduzzi,

\footnotetext{
${ }^{31}$ Los grupos o estratos D y E de la clasificación socioeconómica utilizada en los estudios de mercado en el Brasil están integrados por los hogares de menores ingresos en la escala de estratificación. Por su parte, según la Fundación Getulio Vargas, la denominada clase C se identifica normalmente con la clase media baja. Esta se habría convertido en la más numerosa del Brasil gracias al ascenso socioeconómico de personas que antes pertenecían a las clases D y E.
}

2007). Participar en esa masificación del consumo suele verse y sentirse como pertenecer a la clase media.

El que todos consuman no impide que exista diversidad. Hay "perfiles de consumidores" que tienen más que ver con criterios de edad, por ejemplo. Todo esto contribuye a la desmasificación del consumo y a que existan mayores grados de libertad del consumidor.

A través de ello pueden apreciarse cambios importantes en las formas de vida de las personas. En épocas anteriores, la presión colectiva conducía a su encuadramiento según las relaciones familiares, ocupacionales o clasistas. La modernidad "tardía" ha incrementado el individualismo, expresado en una mayor preocupación por el sí mismo (self), y la oportunidad de aprovechar las alternativas de consumo material y simbólico, que provoca la fragmentación de los consumidores en grupos diferenciados en función de gustos y afinidades, lo que, por lo demás, resulta funcional a la ampliación del mercado.

Este nuevo funcionamiento de la sociedad y de la autopercepción de los individuos amplía el ámbito de la elección personal, permitiendo marcar las diferencias propias del "cierre social": elección del lugar de residencia, el tipo de vivienda, la escuela de los hijos, los gustos gastronómicos y los lugares preferidos para cultivarlos, los espacios de diversión y el consumo cultural. Los estudios de Svampa (2001) sobre la vida en los denominados countries $^{32}$ de la clase media alta argentina y el posterior énfasis en "la vuelta a la ciudad" destacado por Wortman (2010) muestran tanto esa libertad de elección como los cambios en los gustos que se escenifican en tiempos relativamente breves. Del mismo modo, Arellano (2008) presenta el surgimiento en Lima de una nueva clase media, de origen serrano, que no "copia" el comportamiento de los sectores tradicionales de clase media, sino que innova y define su propio estilo de vida, en la elección gastronómica y musical, entre otros.

Sin duda, no todos tienen las mismas posibilidades de consumir. Hay una clase alta afluente, sofisticada, con mayores alternativas de elección. También podría identificarse una clase media alta, más consolidada, con buenos niveles de ingreso y mayores posibilidades de personalizar sus opciones. En contraste, la clase media baja y sobre todo los sectores recién incorporados

\footnotetext{
32 En la Argentina, y en otros países, se denomina así a barrios cerrados o condominios que usualmente se ubican fuera del radio urbano, y que cuentan con alta vigilancia para garantizar la seguridad de sus residentes, que suelen ser personas de ingresos altos o medio altos.
} 
concretan sus aspiraciones de consumo de manera más estandarizada, pero también pueden marcar en ellas cierta diversidad.

\section{Brecha de aspiraciones}

Las personas tienen metas o deseos que esperan poder plasmar a lo largo de su vida. En una sociedad caracterizada por la renovación constante es probable que la distancia entre lo esperado y lo logrado tienda a generar frustración. Los segmentos no competitivos están sometidos a estímulos consumistas que se ven exacerbados por el mayor nivel educativo, la vida urbana y los medios de comunicación de masas, pero carecen de los medios que permitan satisfacer sus aspiraciones, por lo que ven frustradas sus expectativas.

Hay campos, como la conectividad y la comunicación interactiva a distancia, que se expanden en especial hacia

\section{VI}

\section{Conclusiones}

Indudablemente, la situación actual de los estratos medios presenta características novedosas. En el período que va desde 1990 hasta antes de la crisis de 2008 crecieron tanto el número de hogares de clase media como su ingreso promedio. Ello derivó del aumento del PIB de los países combinado con la disminución de la pobreza y una leve mejoría de la distribución del ingreso. Diversos factores posibilitaron esos cambios. En la "historia corta" - los primeros años del nuevo siglo — cabe destacar a nivel macro las mayores facilidades de financiamiento que tuvieron los países de la región y la fuerte demanda por muchos de los productos regionales exportables. En la "historia larga" conviene recordar transformaciones de desarrollo lento, como la reducción de la tasa de dependencia familiar y el aceleramiento de la incorporación de mujeres al mercado laboral, junto con el beneficio del "bono demográfico" (esto es, el que haya más perceptores de ingreso por hogar en relación con la cantidad de sus dependientes). Ello coincidió con la denominada "sociedad de bajo costo", caracterizada por el surgimiento de una industria orientada a abaratar el costo unitario de muchos bienes de consumo "simbólicos", que anteriormente solo podían ser adquiridos por estratos de ingresos superiores, y por la ampliación del crédito con tasas de interés más reducidas al que tuvieron los jóvenes. Lo mismo sucede en el campo de las industrias culturales, en especial la música y la producción y el consumo audiovisual. En estos rubros el abaratamiento de los productos ha conducido a una mayor individuación de las opciones disponibles para amplias capas sociales, generando la paradoja de la "masificación de la opción por singularizar” (Hopenhayn, 2005, pág. 56).

En tal contexto, la pertenencia de las personas a la clase media no estaría dada necesariamente por su inserción ocupacional, y ni siquiera por su ingreso, sino por la condición de consumidor en una sociedad donde es posible acceder a una amplia gama de bienes, que no son uniformes y pueden ser seleccionados de acuerdo con preferencias particulares. La aspiración de las personas es participar en ese nuevo espacio consumidor, y ello es identificado como ser de clase media. Ergo, no necesariamente existe correlación entre condiciones objetivas y percepción subjetiva. acceso personas de bajos ingresos, lo que contribuyó a una dinámica de movilidad social ascendente.

La definición bidimensional de clase media utilizada en este trabajo permite poner en evidencia la incorporación a la clase media de hogares del estrato laboral manual, como resultado de que su ingreso (y consecuentemente su consumo) ha aumentado debido al crecimiento económico de los últimos 16 años. Aun sin mejoras significativas en la distribución del ingreso, el importante crecimiento absoluto del PIB por habitante entre comienzos de la década pasada y mediados de la actual permitió que en varios países subiera el consumo de los hogares de los estratos medio y bajo. Hubo un "desplazamiento" en la distribución del ingreso de los hogares hacia tramos de ingreso más alto. Esto es muy significativo para la estratificación social, aunque no sea perceptible en los análisis de distribución del ingreso entre deciles o quintiles de hogares. Todo contribuyó a elevar la demanda de bienes de consumo de uso cada vez más difundido (productos eléctricos y electrónicos, celulares, acceso a internet, automóvil, entre otros) y tornó más "visible" la amplia penetración de ese tipo de bienes en la población. En estos cambios radica una de las claves explicativas de la mayor heterogeneidad de los estratos medios en términos de tipos de ocupación, 
lugar de residencia y posibilidades de estilos distintos de vida, lo que al mismo tiempo derivó en una mayor homogeneidad en los bienes a que pueden acceder los que se han "incorporado" al estrato medio por la vía del ingreso y el acceso al consumo, ampliado este último por la notable expansión del crédito.

En el punto de partida del trabajo se reconoce que la posición que ocupan hoy los individuos en el mercado laboral es insuficiente para describir la estructura social y delimitar a sus estratos intermedios, por cuanto el carácter de las ocupaciones ha cambiado y han cobrado mayor importancia otras dimensiones, como el consumo y los estilos de vida. Desde la perspectiva ocupacional, la magnitud del estrato medio varió significativamente según el nivel de desarrollo de los países, pero aumentó en todos salvo en uno en que tuvo una pequeña caída $\mathrm{y}$ otro en que se mantuvo constante. El incremento del número absoluto de hogares de estrato medio (56 millones, que elevó el total a 128 millones de hogares en 16 años) permite apreciar mejor el destacado efecto de demostración que generan ciertas pautas de consumo cada vez más difundidas. En los dos países más poblados (el Brasil y México) los aumentos fueron de 28 y 14 millones de hogares, respectivamente.

Hubo importantes cambios en el tamaño y la composición de los hogares, que explican la expansión de los estratos medios en los últimos 15 años. La merma de la fecundidad y de la tasa de dependencia permitió que se acrecentara la participación laboral de las mujeres y todo ello contribuyó a la elevación del ingreso familiar y de las posibilidades de consumo de los estratos medios y bajos.

En la mayoría de los países, el sector medio-bajo concentra entre dos tercios y más de tres cuartas partes del total de los hogares del estrato medio. Y una alta proporción de los asalariados de aquel sector tienen una inserción laboral precaria, con ingresos muy reducidos y a menudo sin contrato y cobertura de seguridad social. El análisis de la segmentación "horizontal" del estrato medio no otorga sustento ni a la hipótesis sobre la pérdida de importancia del Estado como empleador, ni a la relacionada con el aumento del empleo independiente y la correlativa disminución del empleo asalariado en el sector privado.

Si bien se han incrementado las oportunidades de acceso a niveles más altos de educación, simultáneamente se ha producido una devaluación relativa de las oportunidades laborales y de ingreso para quienes logran terminar la educación secundaria. Asimismo, se aprecia que se acrecienta el número de integrantes del estrato bajo con mayor nivel educacional, así como de amplias capas del estrato medio-bajo con educación secundaria completa. Ello se ha traducido en una homogeneización de los ingresos entre ambos estratos y ha provocado una disociación entre el tipo de ocupación y el ingreso que se obtiene.

Finalmente, hay que destacar la importancia de los cambios estructurales que han vivido las sociedades de la región en el período analizado, en especial los derivados del desarrollo excepcional del comercio internacional, con la incorporación de nuevos actores que proporcionaron una enorme capacidad productiva de bienes manufacturados de exportación y se convirtieron asimismo en demandantes de productos de todo tipo. Ello redundó en importantes alteraciones de la estratificación social en los países analizados, que tuvo expresión especialmente relevante en las modificaciones del tamaño y características de las clases medias.
Arellano, Rolando (2008), Valores e ideología: el comportamiento político y económico de las nuevas clases medias en América Latina, Barcelona, Comisión Económica para América Latina y el Caribe (CEPAL)/Centro de Información y Documentación de Barcelona (CIDOB).

Banco Mundial (2006), World Development Report 2006: Equity and Development, Washington, D.C.

Birdsall, Nancy, Carol Graham y S. Pettinato (2000), "Stuck in the tunnel: is globalization muddling the middle class?", Working Paper, $\mathrm{N}^{\mathrm{o}}$ 14, Washington, D.C., Center on Social and Economic Dynamics, The Brookings Institution, agosto.

CEPAL (Comisión Económica para América Latina y el Caribe) (2008a), Panorama social de América Latina, 2008 (LC/G.2402-P), Santiago de Chile, diciembre. Publicación de las Naciones Unidas, $\mathrm{N}^{\circ}$ de venta: S.08.II.G.89. (2008b), Juventud y cohesión social en Iberoamérica: un modelo para armar (LC/G.2391), Santiago de Chile, CEPAL/ AECID/SEGIB/OIJ, Santiago de Chile, octubre.

(2007), Panorama social de América Latina, 2007 (LC/ G.2351-P), Santiago de Chile. Publicación de las Naciones Unidas, $\mathrm{N}^{\circ}$ de venta: S.07.II.G.124.

(2004), Panorama social de América Latina, 2004 (LC/ G.2259-P), Santiago de Chile. Publicación de las Naciones Unidas, $\mathrm{N}^{\mathrm{o}}$ de venta: S.04.II.G.148.

CEPAL/OIT (Comisión Económica para América Latina y el Caribe/ Organización Internacional del Trabajo) (2009), "Coyuntura laboral en América Latina y el Caribe: crisis y mercado laboral", Boletín CEPAL/OIT, $\mathrm{N}^{\circ}$ 1, Santiago de Chile, junio.

Escobar Latapí, Agustín y Laura Pedraza (2010), "Clases medias en México: transformación social, sujetos múltiples", Clases 
medias en América Latina. Retrospectiva y cambios recientes, Rolando Franco, Martín Hopenhayn y Arturo León, México, D.F., CEPAL-SEGIB/Siglo XXI editores.

Espinoza, Vicente (2009), "Entrevista”, ¿Cómo han cambiado la o las clases medias durante los últimos 20 años?, Santiago de Chile, Expansiva, mayo de 2009.

Franco, Rolando y Martín Hopenhayn (2010), "Las clases medias en América Latina: historias cruzadas y miradas diversas", Clases medias en América Latina. Retrospectiva y cambios recientes, Rolando Franco, Martín Hopenhayn y Arturo León, México, D.F., CEPAL-SEGIB/Siglo XXI editores.

Franco, Rolando, Martín Hopenhayn y Arturo León (2010), Clases medias en América Latina. Retrospectiva y cambios recientes, México, D.F., CEPAL-SEGIB/Siglo XXI editores.

Franco, Rolando, Arturo León y Raúl Atria (2007), Estratificación y movilidad social en América Latina. Transformaciones estructurales de un cuarto de siglo, Santiago de Chile, Comisión Económica para América Latina y el Caribe (CEPAL)/LOM ediciones.

Gaggi, Massimo y Edoardo Narduzzi (2007), El fin de la clase media y el nacimiento de la sociedad de bajo coste, Madrid, Editorial Lengua de Trapo.

Hopenhayn, Martín (2005), América Latina desigual y descentrada, Buenos Aires, Editorial Norma.

Kessler, Gabriel y Vicente Espinoza (2007), "Movilidad social y trayectorias ocupacionales en Buenos Aires. Continuidades, rupturas y paradojas", Estratificación y movilidad social en América Latina. Transformaciones estructurales de un cuarto de siglo, Rolando Franco, Arturo León y Raúl Atria, Santiago de Chile, Comisión Económica para América Latina y el Caribe (CEPAL)/LOM ediciones.

Klein, Emilio y Víctor Tokman (2000), "La estratificación social bajo tensión en la era de la globalización”, Revista de la CEPAL, N 72 (LC/G.2120-P), Santiago de Chile, Comisión Económica para América Latina y el Caribe (CEPAL), diciembre.

León, Arturo, Ernesto Espíndola y Camilo Sembler (2010), "Clases medias en América Latina: Una visión de sus cambios en las dos últimas décadas", Clases medias en América Latina. Retrospectiva y cambios recientes, Rolando Franco, Martín Hopenhayn y Arturo León, México, D.F., CEPAL-SEgiB/ Siglo XXI editores.

León, Arturo y Javier Martínez (2007), "La estratificación social en Chile hacia fines del siglo XX", Estratificación y movilidad social en América Latina. Transformaciones estructurales de un cuarto de siglo, Rolando Franco, Arturo León y Raúl Atria, Santiago de Chile, Comisión Económica para América Latina y el Caribe (CEPAL)/LOM ediciones.

Matesanz, David y Andrés Palma (2008), Las clases medias latinoamericanas y España: oportunidades y desafios, Madrid, Observatorio de Política Exterior Española (OPEX)-Fundación Alternativas.

Méndez, María Luisa (2009), "Clases medias en Chile: transformaciones, sentido de pertenencia y tensiones entre proyectos de movilidad", Clases medias en América Latina. Retrospectiva y cambios recientes, Rolando Franco, Martín Hopenhayn y Arturo León, México, D.F., CEPAL-SEGIB/Siglo XXI editores.
(2009), "Entrevista”, ¿Cómo han cambiado la o las clases medias durante los últimos 20 años?, Santiago de Chile, Expansiva, mayo de 2009.

Méndez, María Luisa y Modesto Gayo (2007), "El perfil de un debate: movilidad y meritocracia. Contribución al estudio de las sociedades latinoamericanas", Estratificación y movilidad social en América Latina. Transformaciones estructurales de un cuarto de siglo, Rolando Franco, Arturo León y Raúl Atria, Santiago de Chile, Comisión Económica para América Latina y el Caribe (CEPAL)/LOM ediciones.

Mora y Araujo, Manuel (2008), Vulnerabilidad de las clases medias en América Latina. Competitividad individual y posición social, Barcelona, Comisión Económica para América Latina y el Caribe (CEPAL)/Centro de Información y Documentación de Barcelona (СIDOB).

(2007), "La estructura social de la Argentina: evidencias y conjeturas acerca de la estratificación actual", Estratificación y movilidad social en América Latina. Transformaciones estructurales de un cuarto de siglo, Rolando Franco, Arturo León y Raúl Atria, Santiago de Chile, Comisión Económica para América Latina y el Caribe (CEPAL)/LOM ediciones.

Oliveira, Fabiana Luci de (2010), "Movilidad social y económica en el Brasil. ¿Una nueva clase media?”, Clases medias en América Latina. Retrospectiva y cambios recientes, Rolando Franco, Martín Hopenhayn y Arturo León, México, D.F., CEPAL-SEGIB/ Siglo XXI editores.

Pessoa de Carvalho Filho, Eneuton Dornellas (2002), "Evolução do emprego no Brasil nos anos 60", Tesis de doctorado, Campinas, Instituto de Economía, Universidad de Campinas.

Solimano, Andrés (2008), "The middle class and the development process", serie Macroeconomía del desarrollo, $\mathrm{N}^{\mathrm{o}} 65$ (LC/L.2892-P), Santiago de Chile, Comisión Económica para América Latina y el Caribe (CEPAL), abril. Publicación de las Naciones Unidas, $N^{\text {o }}$ de venta: E.08.II.G.29.

Svampa, Maristella (2001), Los que ganaron, la vida en countries y barrios privados, Buenos Aires, Editorial Biblos.

Toche, Eduardo (2010), "Aproximaciones a la clase media de Lima", Clases medias en América Latina. Retrospectiva y cambios recientes, Rolando Franco, Martín Hopenhayn y Arturo León, México, D.F., CEPAL-SEGIB/Siglo XXI editores.

Torche, Florencia (2006), "Una clasificación de clases para la sociedad chilena", Revista de sociología, № 20, Santiago de Chile, Facultad de Ciencias Sociales, Universidad de Chile.

Torche, Florencia y Guillermo Wormald (2007), "Chile, entre la adscripción y el logro", Estratificación y movilidad social en América Latina. Transformaciones estructurales de un cuarto de siglo, Rolando Franco, Arturo León y Raúl Atria, Santiago de Chile, Comisión Económica para América Latina y el Caribe (CEPAL)/LOM ediciones.

Wilson, Dominic y Raluca Dragusanu (2008), The Expanding Middle: the Exploding World Middle Class and Falling Global Inequality, Nueva York, Goldman Sachs, julio.

Wortman, Ana (2010), "Las clases medias argentinas", Clases medias en América Latina. Retrospectiva y cambios recientes, Rolando Franco, Martín Hopenhayn y Arturo León, México, D.F., CEPALSEGIB/Siglo XXI editores. 